\title{
THE CEREBRAL RESPONSE TO SODIUM NITROPRUSSIDE AND TRIMETHAPHAN CONTROLLED HYPOTENSION
}

\author{
W.W. StOYKa * and H. SchuTz $\dagger$
}

THE EFFECTS of altered arterial blood pressure on cerebral blood flow (CBF) have been well documented by Lassen ${ }^{1.2}$ and Olesen ${ }^{3}$ in man, and by Rapela, ${ }^{4}{ }^{4}$ Waltz ${ }^{5}$ and Yashon $^{6}$ in dogs. The critical determinants of cerebral blood flow are the cerebral perfusion pressure (CPP) and the cerebrovascular resistance (CVR). The CPP is the difference between the driving force of the mean arterial pressure and the intracranial pressure, or the intracranial venous pressure. It has been shown that CBF remains constant over the range from 60 to more than $150 \mathrm{~mm}$ $\mathrm{Hg}^{2}$. This ability to keep CBF constant in the face of altered perfusion pressure has been termed auto-regulation. Below $60 \mathrm{~mm} \mathrm{Hg}$, cessation of autoregulation has been shown by Lassen, ${ }^{2}$ Finnerty, ${ }^{7}$ and Sokoloff. ${ }^{8}$ It is assumed that this is due to the loss of change in vascular resistance when maximal vasodilatation is present. As an adjunct to neurosurgical anaesthesia, pharmacological agents have been used to lower perfusion pressure while maintaining CBF and autoregulation. Sodium nitroprusside and trimethaphan are two agents used to produce controlled hypotension by alterations in vascular resistance.

The purpose of this study was to compare the changes in $\mathrm{CBF}$, cerebral metabolic oxygen consumption $\left(\mathrm{CMRO}_{2}\right), \mathrm{CVR}$, and cardiac output $(\mathrm{CO})$ with sodium nitroprusside and trimethaphan. Based on these results, a delineation of the safe limits for controlled hypotension would be made.

\section{METHODS}

Fourteen unmedicated dogs were induced with thiopentone $5 \mathrm{mg} / \mathrm{Kg}$, the trachea intubated and ventilation controlled with a Harvard animal ventilator. Arterial $\mathrm{CO}_{2}$ tension was kept at $40 \pm 3$ torr or was corrected from $\mathrm{CO}_{2}$ response curves obtained in a previous study. ${ }^{\circ}$ An infra-red analyzer monitored end-tidal $\mathrm{CO}_{2}$. Anaesthesia was maintained with ketamine $2 \mathrm{mg} / \mathrm{Kg}$. The combination of thiopentone and ketamine anaesthesia has been shown to maintain normal CBF and CVR according to Dawson, et al. ${ }^{10}$ Pancuronium bromide was given to maintain muscle paralysis, stabilize $\mathrm{PacO}_{2}$, and assure stability of cardiac output and blood pressure. The femoral artery was cannulated for determining arterial pressure, blood gas analysis and haematology. The femoral vein was cannulated and a Swan-Ganz thermodilution cardiac output catheter enabled measurement of cardiac output by thermodilution and the central venous pressure.

The CBF was measured directly by isolation of the cerebral venous outflow tracts as previously described ${ }^{9}$ and according to the method of Rapela and Green. ${ }^{4}$

-Assistant Professor, Department of Anaesthesia, St. Michael's Hospital and University of Toronto, Toronto, Ontario, Canada.

fDepartment of Neurosurgery, Toronto Western Hospital, Toronto, Ontario, Canada. 
Cerebral venous blood flowed from a burr hole inserted in the superior sagittal sinus after the two petrosal and two transverse sinuses had been entered and occluded. The cerebral venous blood was shunted through an electromagnetic flow probe into the external jugular vein.

All animals were heparinized after the shunt was in place and blood was transfused as necessary to replace surgical loss. A transducer was used to measure venous torcular outflow pressure. A spinal needle was inserted in the cisterna magna and cerebrospinal fluid pressure (CSFP) was monitored. Arterial and venous torcular $\mathrm{P}_{\mathrm{O}_{2}}, \mathrm{P}_{\mathrm{CO}_{2}}$ and $\mathrm{pH}$ were measured with radiometer electrodes. Haemoglobin and oxygen saturation were measured with an I.L. Co-oximeter and the $\mathrm{O}_{2}$ content was calculated. $\mathrm{CMRO}_{2}$ was calculated as the product of the $\mathrm{CBF}$ and the arteriovenous oxygen content difference. Figure 1 illustrates the methods used and the parameters measured in this study.

The presence of autoregulation, secondary to angiotension infusion, was determined in all animals. If autoregulation was intact, a solution of trimethaphan (0.01 per cent) was injected intravenously with an infusion pump. The rate of flow was sufficient to maintain a cerebral perfusion pressure of $80 \mathrm{~mm} \mathrm{Hg}$. At the end of 15 minutes, $\mathrm{CBF}$ a-vO $\mathrm{O}_{2}$ content difference and cardiac output were measured. The rate of flow of trimethaphan was subsequently increased at 15-minute intervals and results obtained for CPP's of 70,60,50,40 and $30 \mathrm{~mm} \mathrm{Hg}$. In a second group of 7 dogs a solution of sodium nitroprusside ( 0.01 per cent) was used to measure the same parameters at similar time intervals and similar perfusion pressures. At the end of each study CMRO.2 and CVR were calculated. The values at a CPP of 80 were taken as baseline values for both agents. Any differences were calculated as a positive or negative percentage change from the baseline.

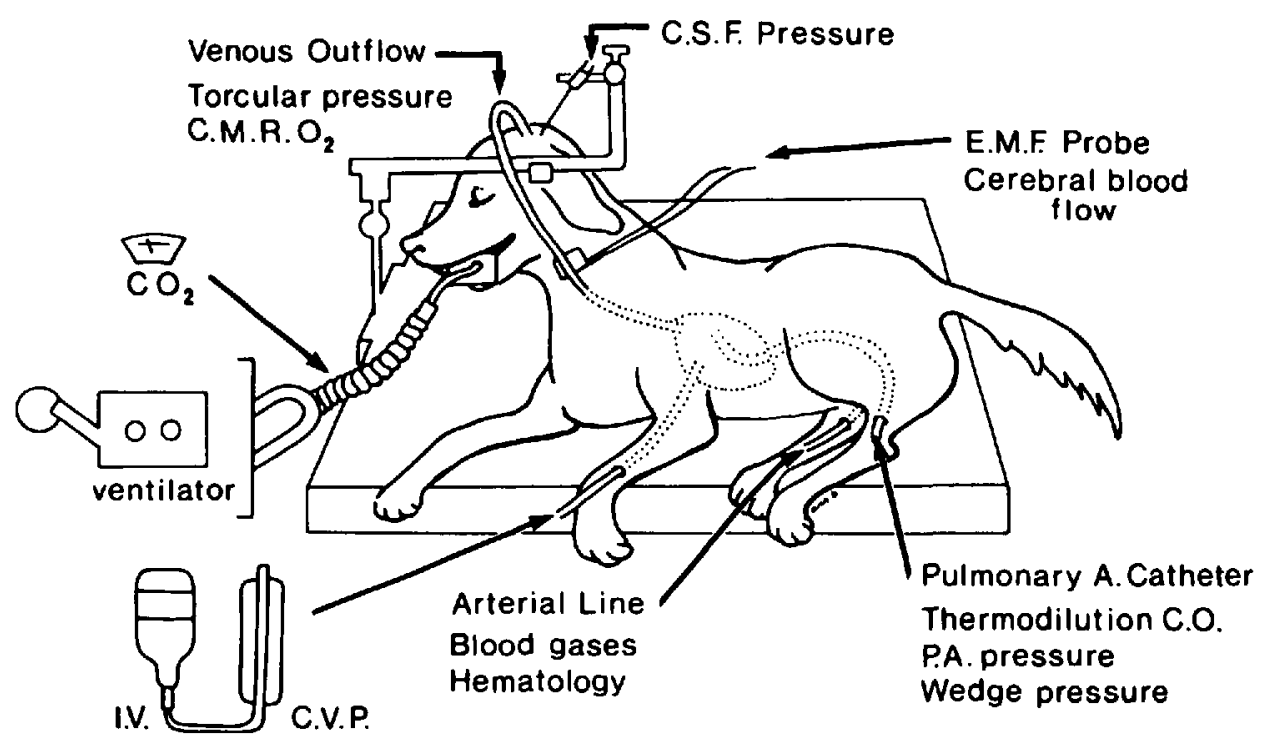

Ficune 1. This illustrates the methodology and parameters which were studied. 


\section{Results}

The response of CBF to altered CPP is shown in Figure 2. The average baseline CBF for all animals was $43.3 \pm 4.5 \mathrm{~mm} / 100 \mathrm{gm} / \mathrm{min}$ at CPP of $80 \mathrm{~mm} \mathrm{Hg}$ and approximates normal values obtained in our previous study. ${ }^{9}$ Data from 14 experiments is presented with the mean values and the standard deviations. The results indicated that both agents caused a 10 per cent to 15 per cent decrease in CBF as the CPP fell to $60 \mathrm{~mm} \mathrm{Hg}$. With trimethaphan, autoregulation was lost below 60 $\mathrm{mm} \mathrm{Hg}$ and the CBF fell as the CPP decreased. However, sodium nitroprusside continued to maintain CBF at a stable level despite the decrease in CPP to $30 \mathrm{~mm}$ $\mathrm{Hg}$. This is presumptive evidence of continued autoregulation at low perfusion pressures with sodium nitroprusside.

Figure 3 shows the response of $\mathrm{CMRO}_{2}$ to altered perfusion pressure. The mean $\mathrm{CMRO}_{2}$ was $3.6 \pm 0.5 \mathrm{mls} / 100 \mathrm{gm} / \mathrm{mm}$, at a CPP of $80 \mathrm{~mm} \mathrm{Hg}$. This compares favourably with our previous study, ${ }^{9}$ substantiates the work of Dawson, et al. ${ }^{10}$ and approximates values obtained in unanaesthetized dogs. ${ }^{11} \mathrm{~A}$ decreased or falling

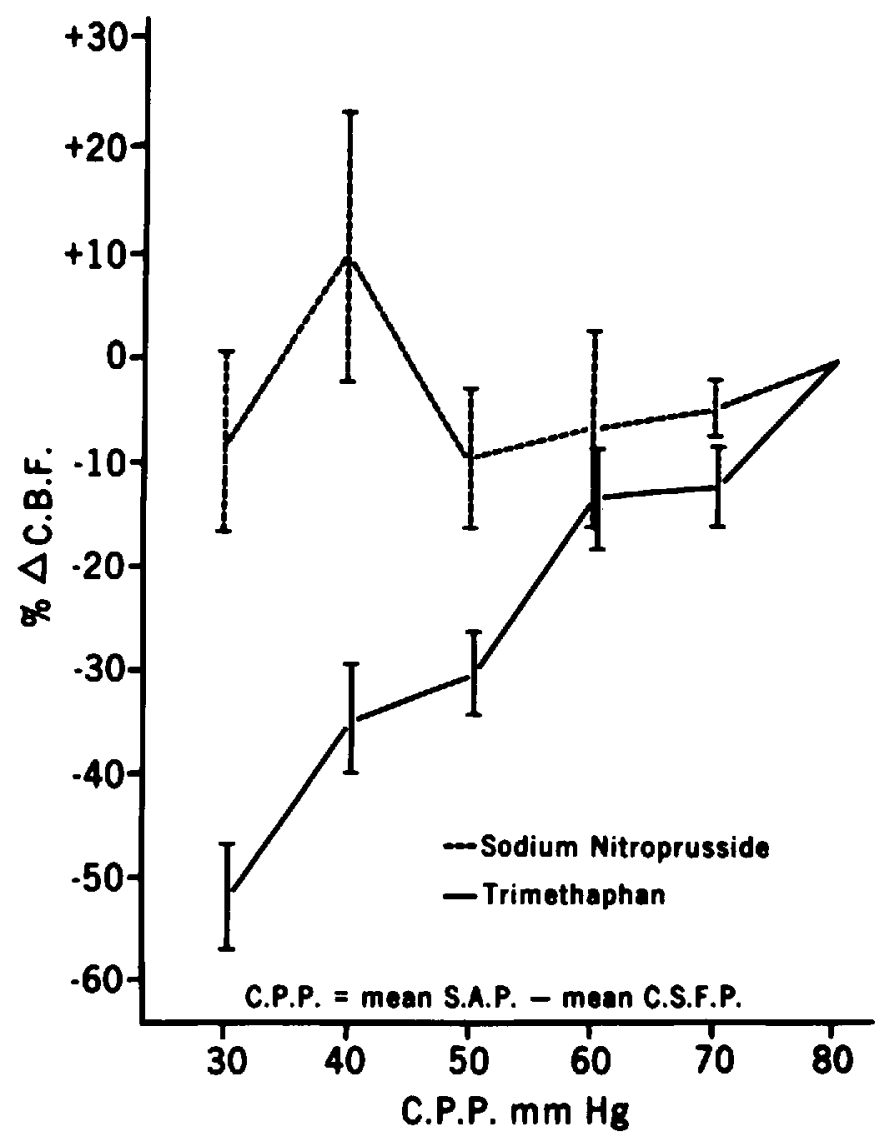

Figure 2. This graph represents the response of CBF to altered arterial perfusion pressure with the two hypotensive agents. 


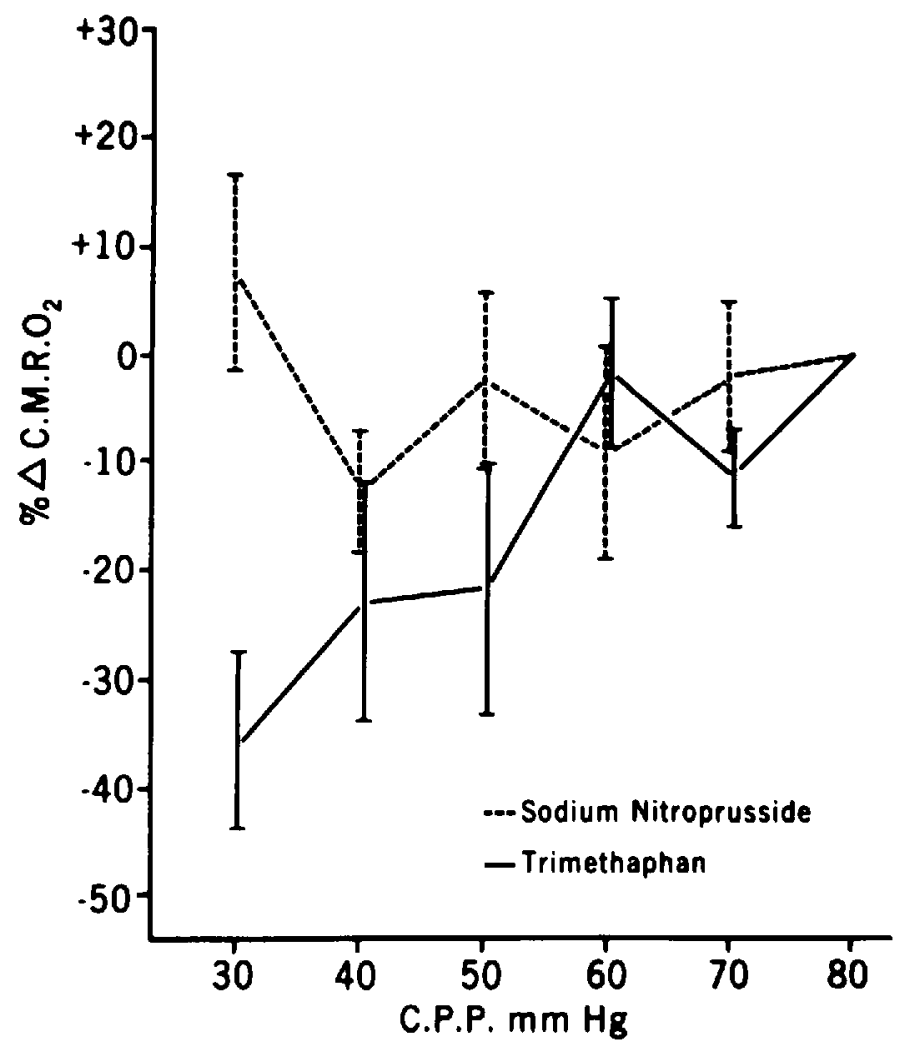

Figure 3. The response of cerebral metabolic oxygen consumption to altered perfusion pressure is compared with two hypotensive agents.

$\mathrm{CMRO}_{2}$ has been shown to be a useful guide to tissue hypoxia or trauma. ${ }^{12}$ With trimethaphan, border-line brain hypoxia was seen when CPP fell to $50 \mathrm{~mm} \mathrm{Hg}$ and CMRO.: had fallen 25 per cent. Frank hypoxia occurred at a CPP of $30 \mathrm{~mm} \mathrm{Hg}$. In contrast, sodium nitroprusside produced no evidence of hypoxia despite low perfusion pressures of $30 \mathrm{~mm} \mathrm{Hg}$. The difference in the results of $\mathrm{CMRO}_{2}$ measurement with the two agents is due to the $\mathrm{CBF}$ changes described and the following CVR and cardiac output changes.

The CVR is calculated from the mean arterial pressure minus the mean venous pressure divided by the CBF. The changes in CVR with altered CPP are shown in Figure 4. The mean CVR was $1.74 \pm 0.04 \mathrm{torr} / \mathrm{ml} / 100 \mathrm{gm} / \mathrm{min}$ which correlates with the normal range of 1.7-1.8. Trimethaphan data revealed on significant change in CVR through the entire range of CPP's. However, sodium nitroprusside produced a progressive decrease in CVR as the CPP was lowered to $30 \mathrm{~mm} \mathrm{Hg}$. This is definite evidence of cerebral vasodilation because we have shown a stable CBF during the same period that the CPP and CVR decreased. The decreased CVR with sodium nitroprusside allowed brain tissue to maintain oxygen extraction despite low perfusion pressures, and thereby prevented brain hypoxia.

The average value for thermodilution cardiac output in our study was $1.29 \pm$ 0.12 litres/min. Cardiac output data in Figure 5 revealed that both agents caused 


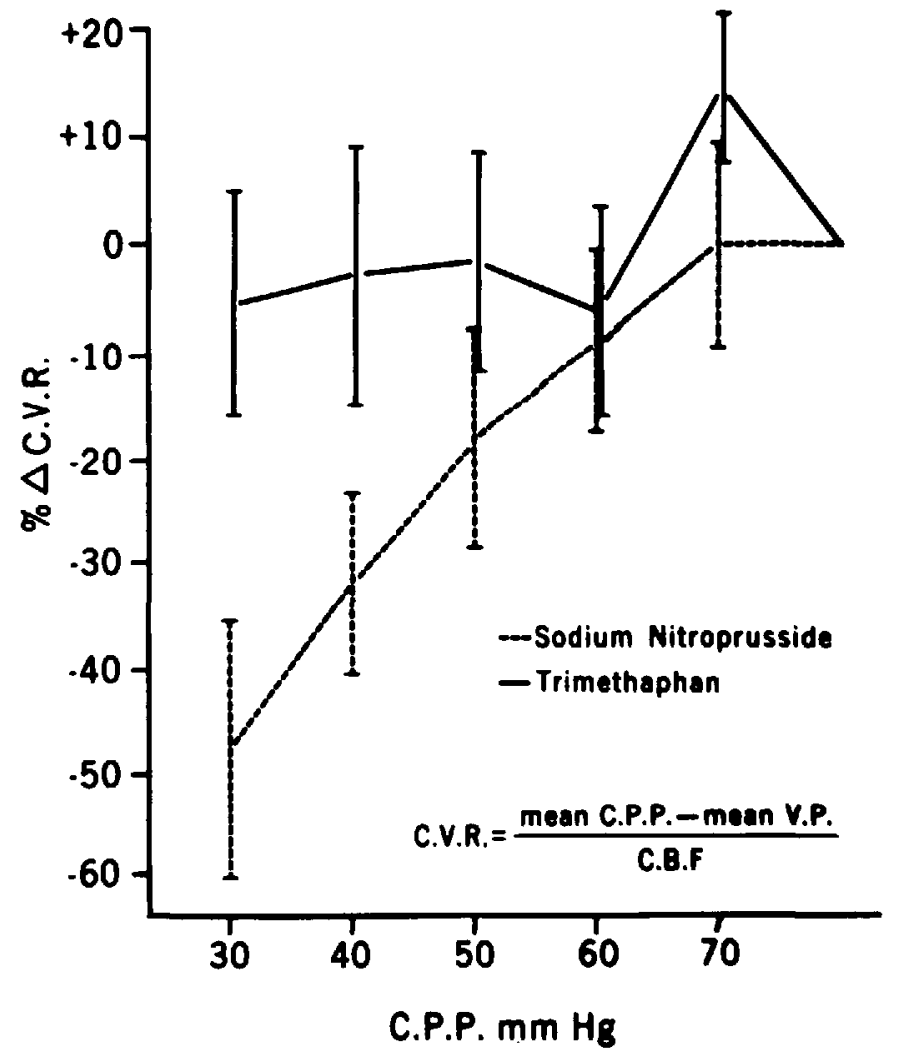

Ficure 4. This graph documents the changes in cerebrovascular resistance with altered cerebral perfusion pressure.

an initial 20 per cent reduction in cardiac output, at a CPP of $60 \mathrm{~mm} \mathrm{Hg}$. Trimethaphan continued to decrease cardiac output to a value of 50 per cent at a CPP of 30 $\mathrm{mm} \mathrm{Hg}$. The trimethaphan reduction in cardiac output correlates with the cerebral blood flow data. It was evident that trimethaphan produced a purely pressure passive system which supplied cerebral blood flow when autoregulation was lost. However, sodium nitroprusside caused no further fall in cardiac output after the initial reduction of 20 per cent. The cardiac output remained stable at a 20 per cent decrease to CPP's of $30 \mathrm{~mm} \mathrm{Hg}$.

\section{Discussion}

Trimethaphan is a ganglionic blocker which has been shown to affect blood pressure by its action on capacitance vessels, primarily by blockade of sympathetic motor reflexes. ${ }^{13}$ The result is a reduction in arterial blood pressure ${ }^{14}$ and decreased cardiac output. ${ }^{14,15}$ The ganglionic blocking effect on the heart as well as a negative inatropic effect similar to beta blockade, ${ }^{16}$ have been postulated to be responsible for cardiac output reduction. In this study, the use of increased doses of trimethaphan produced a progressive decrease in cardiac output to 50 per cent, a continued reduction of CBF to 50 per cent and cerebral hypoxia at low perfusion pressures. 


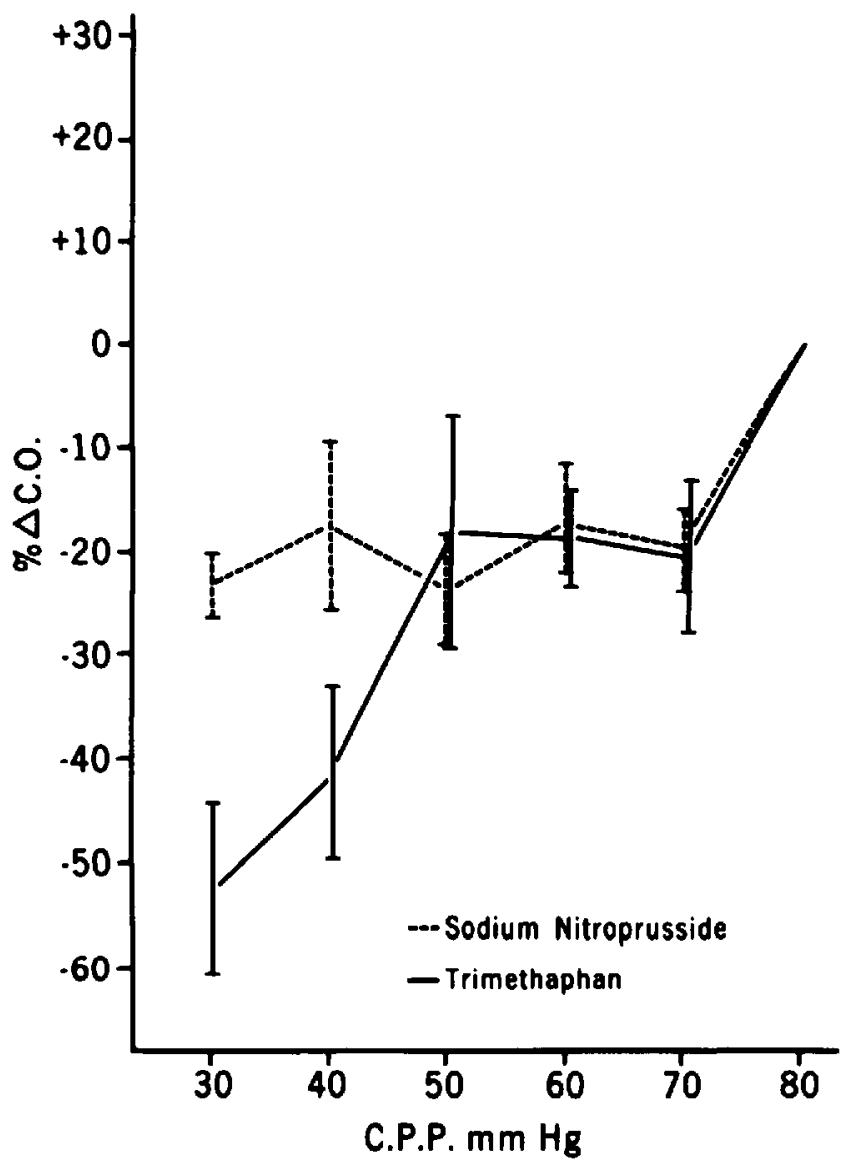

Figure 5. The response of cardiac output to altered cerebral perfusion pressure with two hypotensive agents is shown.

The lack of change in CVR with trimethaphan was the result of several factors. With the simultaneously measured decrease in cardiac output, blood pressure and $\mathrm{CBF}$, mathematically obtained value for CVR appears to show no change. Only if CVR was measured directly, could we verify the actual change. A second explanation by Ponte and Purves ${ }^{18}$ claimed that hypotension, hypoxia and hypercapnia produced reflex cerebral vasodilation due to arterial chemo-receptors and baroreceptors. The dominant role of these neural reflex pathways is dilator in action on the cerebral circulation. Surgical removal of these pathways produced an absent dilator response to hypoxia, a markedly decreased dilator response to hypercapnia and cerebral blood flow was shown to vary directly with perfusion pressure. In our study, the large doses of the ganglionic blocker trimethaphan may have been capable of pharmacologically denervating the cerebral circulation and changing the normal response to hypotension and hypoxia. The resultant purely pressure passive system could be a response to trimethaphan. Another possible explanation for the lack of CVR change may be insidious onset of cerebral hypoxia at low perfusion pressures. During cerebral ischaemia, Wade, et al. ${ }^{17}$ have shown a pro- 
gressive increase in extracellular potassium ions, which was responsible for the production of cerebral vasoconstriction. It is also possible that any or all combinations of these three mechanisms may be responsible for the CVR results in our experiments.

In comparison, sodium nitroprusside is also a rapidly acting drug of short duration which is a potent, predictable and effective agent for lowering blood pressure. The effect is produced primarily on the vascular musculature of resistance and capacitance vessels and is relatively independent of neural vascular control. ${ }^{13}$ It is rapidly broken down by nonenzymatic sulphydryl linkage in red blood cells and other tissues with the production of thiocyanates and free cyanide. ${ }^{10}$ In turn, these are eliminated by the enzymes thiocyanate oxidase and liver rhodenase respectively. Clinically, it has been shown to reduce blood pressure, lower peripheral resistance and cause minimal or no changes in cardiac output. Schlant, et al. ${ }^{20}$ reported an 8.8 per cent decrease in cardiac index in normal supine patients, while Bhatia, et al. ${ }^{14}$ documented a 10 per cent reduction of cardiac output in hypertensive patients. Styles, et al. ${ }^{21}$ showed decreased cardiac output in awake patients and a 22 per cent increase in anaesthetized patients. In our study, nitroprusside produced an 8 per cent decrease in $\mathrm{CBF}$, a 20 per cent decrease in cardiac output and a 50 per cent decrease in CVR at the CPP of $30 \mathrm{~mm} \mathrm{Hg}$. The end result was a continuation of autoregulation of $\mathrm{CBF}$ to $30 \mathrm{~mm} \mathrm{Hg}$. Concomitant with these changes no evidence of cerebral hypoxia was seen.

The maintenance of normal cerebral oxygenation at low perfusion pressures with sodium nitroprusside is due to multiple factors. The singular change was decreased CVR through vasodilatation which effectively reduced the work and energy requirements necessary to maintain normal function. The decreased CVR helped to prevent brain hypoxia by allowing increased tissue oxygen extraction as shown by increased arterio-venous oxygen content differences. The absence of hypoxia prevented the release of intracellular potassium ions and subsequent vasoconstriction. It is also thought that sodium nitroprusside is capable of causing potassium ions to move into or stay intracellularly. The results indicate that sodium nitroprusside should be the agent of choice when hypotension below the range of autoregulation $(60 \mathrm{~mm} \mathrm{Hg}$ ) is required. It is expected to be beneficial when brain trauma or hypoxia is present, when extremes of position or posture may further impede cardiac function, and in cases where diagnostic eye signs are required postoperatively. It is the agent of choice in our unit and has been used without complication in 56 patients to date.

A note of caution is presented at this time. Although no evidence of tachyphylaxis has been shown, a recent case of failure to respond to sodium nitroprusside was reported. Continued administration resulted in overdosage and death due to cyanide intoxication. The absence of a response to a dose of 1 to 2 micrograms per minute per kilogram of body weight after 5 to 10 minutes of therapy, requires immediate cessation of the drug. Continued administration without a hypotensive response is a warning and a consideration for treatment. The clinical manifestations of asphyxia, tachypnoea and cyanosis are indications for immediate therapy. In an acute case of cyanide intoxication, amyl-nitrite inhalations, intravenous sodium nitrite and sodium thiosulphate are used. ${ }^{22}$ Nitrites have the ability to form methae- 
moglobin, which combines with cyanide ions to form the relatively non-toxic cyanomethaemoglobin. Nitroprusside intoxication is a rare occurrence probably due to an enzyme disturbance which can only be identified when there is no response to nitroprusside. Further diagnosis is aided by elevation of sodium thiocyanate levels which increase as the infusion is continued. Fortunately, however, the situation of no response to sodium nitroprusside is extremely rare, and does not warrant the removal of this extremely useful agent.

\section{RésumÉ}

Cette étude avait pour but d'établir la marge de sécurité associée à l'emploi d'hypotension controllée en neuro-chirurgie, hypotension produite soit avec du Trimethaphan ou du Nitro-prussiate. Ces agents par leur action sur la résistance vasculaire permettent de diminuer la pression de perfusion cérébrale (C.P.P.) tout en maintenant le flot sanguin cérébral (C.B.F.) et le mécanisme d'autorégulation.

L'étude a porté sur deux groupes de sept chiens chacun. Les chiens du permier groupe ont reçu du Trimethaphan, ceux du second du Nitroprussiate. On a étudié les paramètres suivants: flot sanguin cérébral $(\mathrm{CBF})$, consommation d' $\mathrm{O}_{2}$ cérébrale $\left(\mathrm{CMRO}_{2}\right)$, résistance vasculaire cérébrale (CVR) et débit cardiaque.

On a observé que pour une diminution du même ordre du flot sanguin cérébral, avec pression de perfusion supérieure à $60 \mathrm{~mm} \mathrm{Hg}$, il y a conservation de l'autorégulation; au-dessous de $60 \mathrm{~mm} \mathrm{Hg}$ de pression de perfusion il y a perte du mécanisme d'autorégulation avec le Triméthaphan et conservation de ce mécanisme avec le Nitroprussiate, mème à des pressions de perfusion basses, le débit sanguin cérébral se maintient stable, grâce à une vasodilatation (chute de la résistance vasculaire cérébrale parallèle à la chute de la pression de perfusion. Ce mécanisme permet une extraction adéquate d'oxygène au niveau cérébral.

Par ailleurs, avec le Triméthaphan aux mèmes basses pressions de perfusion, on observe une diminution de l'extraction cérébrale $\mathrm{d}^{\prime} \mathrm{O}_{2}$ traduisant une hypoxie; contrairement à ce qu'on observe avec le Nitroprussiate, il y a maintien de la résistance vasculaire cérébrale, le flot sanguin cérébral devenant ainsi dépendant de pression de perfusion. La diminution initiale de débit cardiaque observée avec les deux agents devient plus prononcée à mesure qu'on augmente les doses de Trimethaphan, phénomène qui n'est pas observé avec le Nitroprussiate.

\section{ACKNOWLEDGMENTS}

The authors wish to acknowledge the assistance of the Anaesthesia Research Laboratory, St. Michael's Hospital, under the direction of the Chief Technician, Mr. Colin Kay. This study was supported in part by the St. Michael's Hospital Research Society and the Ontario Heart Foundation which made thermodilution cardiac output determinations possible for routine measurement. Parke-Davis gratuitously supplied Ketalar for research purposes.

\section{REFERENCES}

1. LAsSEN, N.A. Autoregulation of cerebral blood flow. Circ. Res. 15: 201 (1964).

2. LAssen, N.A. Cerebral blood flow and oxygen consumption in man. Physiol. Rev. 39: 183 (1959). 
3. Olesen, J. Quantitative evaluation of normal and pathological cerebral blood flow regulation to perfusion pressure. Arch. Neurol. 28: 143 (1973).

4. Rapela, C.E. \& Green, H.D. Autoregulation of canine cerebral blood flow. Circ. Res. 15: 205 (1964).

5. WALtz, A.G. Effect of blood pressure on blood flow in ischemic and in non-ischemic cerebral cortex. Neurology 18: 613 (1968).

6. Yashon, M.D., Locke, G.E., Bingham, W.G., Wiederholt, W.C., \& Hunt, W.E. Cerebral function during profound oligemic hypotension in the dog. J. Neurosurg. 34: 494 (1971).

7. Finneaty, F.A., Witkin, L., \& Fazekas, J.F. Cerebral hemodynamics during cerebral ischemia induced by acute hypotension. J. Clin. Invest. 33: 1227 (1954).

8. Sokoloff, L. The cerebral circulation. Mills, L.C. \& Moyer, J.H. (Eds.), Shock and Hypotension. New York: Crane \& Stratton, pp. 141-149 (1965).

9. Stoyka, W.W. \& Schutz, H. Cerebral response to hypocapnia in normal and brain injured dogs. Canad. Anaesth. Soc. J. $21: 205$ ( 1974 ).

10. Dawson, B., Michenfelden, J.D., \& TheYe, R.A. Effects of ketamine on canine cerebral blood flow and metabolism: modification by prior administration of thiopental. Anaesth. and Analg. 50: 443 (1971).

11. Fink, B.R. \& Haschke, R.H. Anaesthetic effects of cerebral metabolism. Anaesthesiology 39: 199 (1973).

12. Tabaddor, K., Bhushan, C., Pevsner, P.H., \& Walker, A.E. Prognostic value of CBF and $\mathrm{CMRO}_{2}$ in acute head trauma. J. Trauma $12: 10533$ (1972).

13. Косн-Wesen, J. Hypertensive emergencies. N. Engl. J. Med. 290: 211 (1974).

14. Bhatia, S.K. \& Frohlich, E.D. Hemodynamic comparison of agents useful in hypertensive emergencies. Am. Heart J. 85: 367 (1973).

15. Scott, D.B., Stephen, G.W., Marshal.l, R.L., Jenkinson, J.L., \& MacRae, W.R. Circulatory effects of controlled arterial hypotension with trimethaphan during nitrous oxide halothane anaesthesia. Brit. J. Anaesth. 44: 523 (1972).

16. Stephen, G.W., Davie, I.T., \& Scotr, D.B. Haemodynamic effects of beta receptor blocking drugs during nitrous oxide halothane anaesthesia. Brit. J. Anaesth. 43: 320 (1971).

17. Ponte, J. \& Punves, M.J. The role of the carotid body chemoreceptors and carotid sinus baroreceptors in the control of cerebral blood vessels. J. Physio. 237: 315 (1974).

18. WAde, J., Amtorp, O., \& Sonenson, S.C. Increase in the potassium concentration in brain extracellular fluid as a cause of the "no flow" state following cerebral ischemia. Acta Physiologica Scandanavica 91 : 49 (1974).

19. Page, I.H., Corcoran, A.C., Dustan, H.P., \& Koppanyi, T. Cardiovascular actions of sodium nitroprusside in animals and hypertensive patients. Circulation. 11: 188 (1955).

20. Schlant, R.C., Tsagaris, T.S., \& Robertson, R.J. Studies on the acute cardiovascular effects of intravenous sodium nitroprusside. Am. Heart J. 9: 51 (1962).

21. Styles, M., Coleman, A.J., \& Leary, W.P. Some hemodynamic effects of sodium nitroprusside. Anaesthesiology 38: 173 (1973).

22. Swinyand, E.A. Noxious gases and vapours. Goodman, L.S. \& Gilman, A. (Eds.). The pharmacological basis of therapeutics, 4th ed. New York: Macmillan Co., pp. 935-936 (1970). 